\title{
Short-term effects of surface dust: alleviating photoinhibition of cotton under high irradiance in the Tarim Basin
}

\author{
L. $\mathrm{LI}^{*, * *, * * *,+}$ and G. MU**
}

State Key Laboratory of Desert and Oasis Ecology, Xinjiang Institute of Ecology and Geography, Chinese Academy of Sciences, Urumqi 830011, China* Cele National Station of Observation and Research for Desert-Grassland Ecosystems, Cele 848300, China ${ }^{* *}$ Key Laboratory of Biogeography and Bioresources in Arid Zone, Chinese Academy of Sciences, Urumqi 830011, China***

\begin{abstract}
Dust deposition on leaf surfaces can impact the growth and physiological traits of plants. We carried out a field experiment to investigate short-term effects of light surface dust on photosynthesis of cotton in the Tarim Basin using chlorophyll fluorescence and gas-exchange techniques. JIP-test analysis of OJIP curves showed that the total performance index for leaves without dust decreased by $32 \%$ at noon compared to the morning value. High irradiance at noon reduced actual quantum yield of PSII and increased nonphotochemical quenching for leaves without dust, showing photoinhibition. It suggested that light surface dust alleviated photoinhibition of cotton to high irradiance on a short-term basis. For the leaves without dust, high irradiance induced photoinhibition not only with respect to the photochemistry reactions but the biochemical pathways of $\mathrm{CO}_{2}$ fixation. Mechanisms such as thermal dissipation and enhanced electron flux to PSI protected the photosynthetic apparatus under high irradiance.
\end{abstract}

Additional key words: chlorophyll a fluorescence; dust retention; electron transport; photosynthetic rate.

Dust from windblown sand exists widely in the atmosphere (Akhlaq et al. 2012). Dust particles can be carried to various distances by wind, after which they are redeposited onto the surface (Shao 2008). Vegetation can effectively adsorb particles in the air by capturing the airborne particle matter on their leaves (Prusty et al. 2005). In turn, foliar retention of particles can disturb the physical traits of the leaf surface. In the past decade, it was widely reported that dust accumulation on the leaf surface affects the surface morphological structure (Pourkhabbaz et al. 2010, Rai et al. 2010), photosynthesis (Naidoo and Chirkoot 2004), transpiration (Sharifi et al. 1997), and biochemical characteristics concerning membrane injury (Neves et al. 2009). Heavy dust deposition reduces a pigment content and adversely impacts growth when an overall leaf energy deficit occurs over a long time scale (Sharifi et al. 1997, Nanos and Ilias 2007).

Light is essential for plant photosynthesis, but excess light can inhibit photosynthetic activity and even damage the photosynthetic machinery (Takahashi and Badger 2011). Light stress is a normal situation and a common phenomenon during plant photosynthesis (Wilhelm and Selmar 2011). Dust deposition on the leaf can hinder light and decrease PAR that reaches the photosynthetic tissues (Sharifi et al. 1997). As a consequence, heavy dust accumulation on the leaf surface may cause an energy deficit by significantly reducing sun radiation, resulting in a decrease in photosystem activity (Hirano et al. 1995). However, we speculate that a light dust accumulation on the leaf surface may produce positive physiological

Received 27 August 2016, accepted 17 May 2017, published as online-first 22 June 2017.

${ }^{+}$Corresponding author; e-mail: 1i 1y@ms.xjb.ac.cn

Abbreviations: $\mathrm{F}_{0}$ - minimum quantum yield of the dark-adapted state; $\mathrm{F}_{\mathrm{m}}$ - maximal quantum yield of the dark-adapted state; $\mathrm{F}_{\mathrm{m}}$ ' - maximal quantum yield of the light-adapted state; $\mathrm{F}_{\mathrm{t}}-$ steady-state fluorescence yield of the light-adapted state; $g_{\mathrm{s}}-$ stomatal conductance; $\mathrm{PI}_{\mathrm{t}}$ - performance index for energy conservation from photons absorbed by PSII antenna to the reduction of PSI acceptors; $P_{\mathrm{N}}$ - net photosynthetic rate; $\mathrm{RC}$ - reaction center; RC/ABS - reaction center density per absorption flux; $\varphi_{\mathrm{D} o}$ - dissipated energy flux; $\varphi_{E_{o}}$ - quantum yield of the electron transport flux from $\mathrm{Q}_{\mathrm{A}}$ to $\mathrm{Q}_{\mathrm{B}} ; \varphi_{\mathrm{Po}}$ - maximum quantum yield of primary PSII photochemistry; $\Phi_{\mathrm{f}, \mathrm{D}}$ - quantum yield of constitutive nonregulatory (basal or dark) dissipation processes consisting of fluorescence emission and heat dissipation; $\Phi_{\mathrm{NPQ}}$ - quantum yield of regulatory light-induced nonphotochemical quenching; $\Phi_{\mathrm{P}}$ - actual quantum yield of PSII photochemistry for the light-adapted state; $\delta_{\text {Ro }}$ - efficiency with which an electron from Qв is transferred until PSI acceptors.

Acknowledgements: The work was financially supported by National Natural Science Foundation of China (No. 41271494, No. 41671486). We thank editors for help in preparation of the manuscript and some reviewers for their valuable suggestions. 
impacts by alleviating the light intensity absorbed by the leaf surface under high radiance, especially on a short-term basis.

The Tarim Basin in northwestern China, which is located in the center of the Eurasian continent, has a hot and dry climate because of the influence of high mountains in the region. Annual precipitation in the desert area is only $10.7 \mathrm{~mm}$, while evaporation exceeds $3,800 \mathrm{~mm}$. The rainfall events are rare (Yang 1987). Dry and hot environments resulted in heavy desertification. The Tarim Basin has the second largest mobile desert in the world, Taklimakan Desert, which is one of the centers with a high dust storm frequency in China (Zhao et al. 2013). The number of days with dust storms typically exceeds $100 \mathrm{~d}$ each year (Liu et al. 2010). Windblown dust is an important environmental problem that affects human life and ecological conditions in the Tarim Basin. The dust particles spread with wind and are deposited onto the leaf surfaces of plants around oases when wind speeds slow down. The accumulation of particles on leaf surfaces is highly apparent (Lin et al. 2015). For example, our data show that dust accumulation on leaf surfaces exceeds 1.8 $\mathrm{mg} \mathrm{cm}{ }^{-2}$ for cotton and $3 \mathrm{mg} \mathrm{cm}^{-2}$ for Ulmus pumila after a sandstorm (unpublished data). Even on clear days, dust retention on leaf surfaces is obvious due to air-borne dust.

During summer in the Tarim Basin, the irradiance at noon exceeds $1,500 \mu \mathrm{mol}$ (photon) $\mathrm{m}^{-2} \mathrm{~s}^{-1}$. Consequently, plant leaves are often exposed to high irradiance levels. Foliar dust retention may prevent light absorption by leaves. Cotton is widely planted in the Tarim Basin due to its high production and economic value. We carried out an experiment to investigate the short-term effects of surface dust on photosynthesis in cotton under high irradiance in the Tarim Basin; our experiments focused on measurements of PSII activity and $\mathrm{CO}_{2}$ fixation. The hypothesis that light dust accumulation might affect cotton photosynthesis was tested and the response mechanism to high irradiance was discussed.

The experiment was carried out at a cotton field in Alar of the Xinjiang autonomous region of China in August 2013. The site is located in the north of the Tarim Basin where sandstorms occur frequently. The cotton plants were cultured in a field of approximately 30 ha and were well irrigated. Cotton leaves covered with dust were considered as the treated ones and leaves without dust were used as the controls. In order to obtain leaves without dust, we rinsed the leaves and then enclosed them in a thin paper bag throughout the night to prevent dust retention. All leaves used in this experiment were the second leaves from the top of the plants. All measurements were consistently conducted on the main stem flag leaves to minimize agerelated heterogeneity of leaf tissue between the plants on each sampling date. We completed our measurements within two days, when PAR exceeded 1,500 $\mu$ mol(photon) $\mathrm{m}^{-2} \mathrm{~s}^{-1}$ at noon.

We collected ten individuals at random. The second fully developed leaves from the top of each plant were sampled and rinsed with distilled water in an ultrasonic washing machine for $30 \mathrm{~min}$. Subsequently, the distilled water with dust was dried until a constant mass was reached, and then the dust was weighed and grain sizes were analyzed. The leaves were scanned to determine the leaf area. Dust retention was quantified as dust mass per $\mathrm{cm}^{2}$ and was $0.32 \pm 0.04 \mathrm{mg} \mathrm{cm}{ }^{-2}$. Dust grain sizes in the range of $0.5-140 . \mu \mathrm{m}<10 \mu \mathrm{m}$ constituted about $6.7 \%$ and $>10 \mu \mathrm{m}$ comprised over $90 \%$.

The chlorophyll (Chl) a fluorescence induction kinetics was measured using a Pocket PEA fluorimeter (Hansatech, Norfolk, UK). The measurements were carried out in the morning at 6:00 and at noon (12:00) after the leaves were dark-adapted for 30 min using leaf clips. Each plant group included 13 replicates. Light intensity (at $660 \mathrm{~nm}$ ) of $3,500 \mu \mathrm{mol}$ (photon) $\mathrm{m}^{-2} \mathrm{~s}^{-1}$ was provided to a 4-mm-diameter leaf to generate maximal fluorescence for all measurements. The fast fluorescence rise kinetics was recorded from $10 \mu \mathrm{s}$ to $3 \mathrm{~s}$. The fluorescence intensity at $20 \mu \mathrm{s}, 300 \mu \mathrm{s}, 2 \mathrm{~ms}, 30 \mathrm{~ms}$, and the maximum fluorescence $\left(\mathrm{F}_{\mathrm{m}}\right)$ were measured. The relative parameters were obtained according to the JIP-test analysis to quantify PSII behavior (Strasser et al. 2004, Jiang et al. 2008, Stirbet and Govindjee 2011). Chl $a$ fluorescence parameters were measured using a portable fluorometer (PAM-2100; Heinz Walz, Nuremberg, Germany). The measurements were carried out at 6:00 in the morning after the leaves were kept under dark conditions for the whole night. Ten leaves tagged were dark-adapted for $30 \mathrm{~min} . \mathrm{F}_{0}$ was measured using modulated light that was sufficiently low $[<0.1$ $\mu \mathrm{mol}($ photon $) \mathrm{m}^{-2} \mathrm{~s}^{-1}$ ] so as to not induce any significant variable fluorescence, and $\mathrm{F}_{\mathrm{m}}$ was determined after a $0.8-\mathrm{s}$ saturating pulse at $8,000 \mu \mathrm{mol}$ (photon) $\mathrm{m}^{-2} \mathrm{~s}^{-1}$ applied to dark-adapted leaves. Under natural radiation at noon, following adaptation to full light, leaves were measured to obtain $\mathrm{F}_{\mathrm{t}}$ and $\mathrm{F}_{\mathrm{m}}{ }^{\prime}$. $\Phi_{\mathrm{p}}$ was calculated as $\left(\mathrm{F}_{\mathrm{m}}{ }^{\prime}-\mathrm{F}_{\mathrm{t}}\right) / \mathrm{F}_{\mathrm{m}}$ '. Two nonphotochemical fluorescence parameters $\Phi_{\mathrm{f}, \mathrm{D}}\left(=\mathrm{F}_{\mathrm{t}} / \mathrm{F}_{\mathrm{m}}\right)$ and $\Phi_{\mathrm{NPQ}}\left(=\mathrm{F}_{\mathrm{t}} / \mathrm{F}_{\mathrm{m}}{ }^{\prime}-\mathrm{F}_{\mathrm{t}} / \mathrm{F}_{\mathrm{m}}\right)$ were calculated (Lazár 2015). Gas-exchange parameters were measured at noon using a portable gas-exchange system (GFS-3000, Heinz Walz, Nuremberg, Germany). Net photosynthetic rate, stomatal conductance and the leaf temperature were measured. Three tagged leaves under natural sunlight were chosen. The system was zeroed prior to each set of measurements. All measurements were performed at ambient temperature and humidity and at $\mathrm{CO}_{2}$ concentration of $350 \mathrm{mmol} \mathrm{mol}^{-1}$ inside the leaf chamber. Means comparisons were performed using an independent-samples $T$ test using the SPSS program (13.0) at the 5\% level.

Our results confirmed that light surface dust alleviated photoinhibition at noon on a short-term basis. Dust accumulation had a positive influence on the fluorescence rise curves and the total performance index $\left(\mathrm{PI}_{t}\right)$ of the cotton leaves under high light at noon (Fig. 1, Table 1). The fast fluorescence rise kinetics is often used to quantify plant environmental stress responses and to directly assess plant health (Force et al. 2003). Based on the JIP-test analysis, 
$\mathrm{PI}_{t}$ is a parameter that integrates all information on PSII functions, including the various changes in the antenna, reaction center and energy fluctuations (Strasser et al. 2000). The $\mathrm{PI}_{t}$ value for dust-covered leaves was 9.6\% higher and that for leaves without dust was 32\% lower at noon compared to the morning values (Table 1). High irradiance at noon inhibited the activity of the electron transport chain of PSII in leaves without dust but enhanced it slightly in dust-covered leaves.

For leaves without dust, high irradiance induced a decrease in $\Phi_{\mathrm{P}}$ and $\Phi_{\mathrm{NPQ}}$ but an increase in $\Phi_{\mathrm{f}, \mathrm{D}}$ (Table 1). Both the actual quantum yield of PSII photochemistry for a light-adapted state $\Phi_{P}$ is widely used to quantify the downregulation of PSII electron transport (Li et al. 2012). The decreased $\Phi_{\mathrm{P}}$ in leaves without dust at noon indicated photoinhibition. The excess energy was dissipated as nonphotochemical quenching. The quantum yield of constitutive nonregulatory (basal or dark) dissipation processes, consisting of fluorescence emission and heat dissipation $\Phi_{\mathrm{f}, \mathrm{D}}$ and quantum yield of regulatory light-induced nonphotochemical quenching $\Phi_{\mathrm{NPQ}}$, are used to quantify the ratio of the nonphotochemical processes (Humplík et

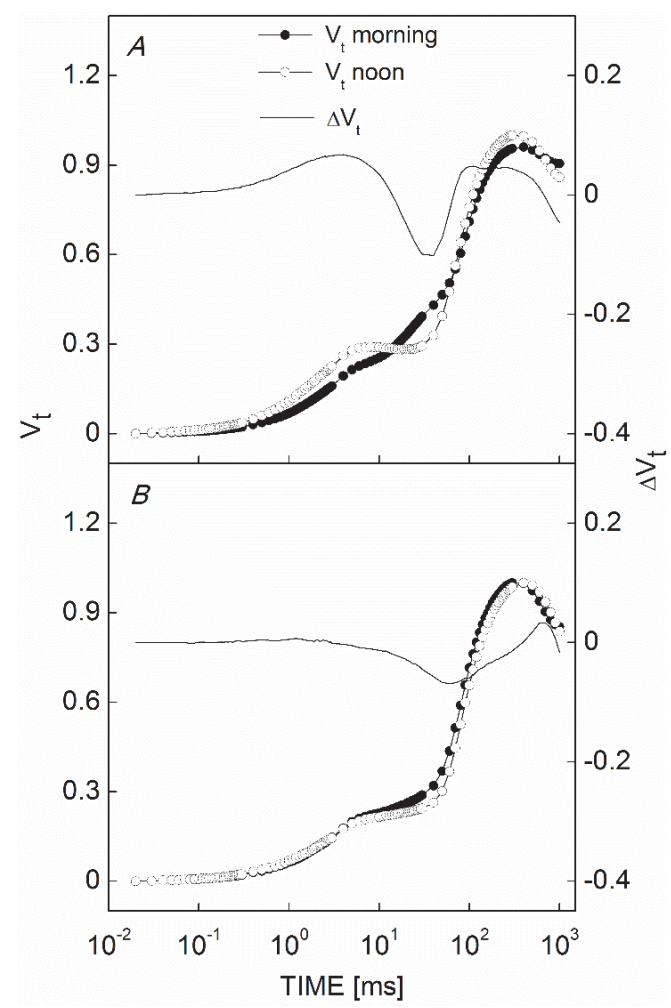

Fig. 1 Relative variable fluorescence $\left[\mathrm{Vt}=\left(\mathrm{F}_{\mathrm{t}}-\mathrm{F}_{0}\right) /\left(\mathrm{F}_{\mathrm{m}}-\mathrm{F}_{0}\right)\right]$ and kinetic difference of $\mathrm{Vt}[\Delta \mathrm{Vt}=\mathrm{Vt}$ (noon) $-\mathrm{Vt}$ (morning) $]$ in cotton leaves not covered $(A)$ and covered with dust $(B)$. The fast fluorescence rise curves were measured in the Tarim Basin in China in the morning or at noon in August 2013. Each value represents the means of at least 13 plants. Before the measurements, leaves were dark-adapted for $30 \mathrm{~min}$. The $\mathrm{x}$-axis is plotted on a logarithmic time scale $(0.01 \mathrm{~ms}$ to $1 \mathrm{~s})$. al. 2015). The higher value in $\Phi_{\mathrm{f}, \mathrm{D}}$ for leaves without dust indicated that high irradiance induced the damage in PSII apparatus, while leaves with dust and a higher $\Phi_{\mathrm{NPQ}}$ showed a higher regulating capacity for high irradiance compared to leaves without dust.

In addition, the accumulation of leaf dust significantly increased $g_{\mathrm{s}}$ and slightly enhanced $P_{\mathrm{N}}$, but this effect was not significant (Table 1). It has been reported that heavy dust on leaf surfaces increases the leaf temperature and causes heat stress, due to a decrease in $g_{\mathrm{s}}$ and $P_{\mathrm{N}}$ (van Heerden et al. 2007, Nanos and Ilias 2007). On the contrary, in the present study, a light dust cover had no effect on leaf temperature (data not shown) and $P_{\mathrm{N}}$ but elevated $g_{\mathrm{s}}$. The increase in $g_{\mathrm{s}}$ suggested that the light dust coating might change the boundary layer conditions and raise the humidity of the leaf surface due to dust hydrophilic properties. However, this cannot be directly confirmed by our experiment.

In leaves not covered with dust, increased thermal dissipation and electron flux to PSI protected the photosynthetic apparatus under high irradiance at noon. The transient fluorescence curves indicated that high irradiance at noon reduced the fluorescence intensity from the $\mathrm{J}$ to the I step, but increased it in the IP phase (Fig. 1). Schansker et al. (2005) stated that the phases of the OJIP curves reflect different reduction processes of the electron transport chain. The JI phase represents the kinetic properties of reduction/oxidation of the plastoquinone pool, while the IP phase reflects the reduction of the PSI acceptor side and the rate-limiting step of the photosynthetic electron transport chain (Schansker et al. 2005, Lazár 2006, Gomes et al. 2012). Thus, a decrease in the JP phase shows that high irradiance decreases a plant's capacity to reduce $\mathrm{Q}_{\mathrm{A}}$, whereas an increasing IP phase is associated with an increase in the transfer of electrons to the PSI acceptor side. In the JIP-test analysis, the yield $\left(\varphi \mathrm{p}_{\mathrm{o}}, \psi_{\mathrm{o}}\right.$, and $\left.\varphi_{\mathrm{Eo}}\right)$ and $\mathrm{RC} / \mathrm{ABS}$ were reduced, but $\varphi_{\text {Do }}$ increased (Table 1), indicating that more RCs were inactive and more energy was dissipated (Strasser et al. 2004). In addition, high irradiance reduced $\delta_{\text {Ro, indicating }}$ that the transfer of electrons to the PSI acceptor side was enhanced, and overexcitation energy pressure was alleviated (Zivcak et al. 2014). These mechanisms downregulated the activity of PSII but protected the PSII apparatus under high irradiance in leaves without dust (Raven 2011). This is supported by the results from the desert plant Hexiniapoly dichotoma (Li et al. 2015). Similarly, thermal dissipation and enhanced electron flux to PSI protect the photosynthetic apparatus under drought (Campos et al. 2014), salinity (Lu and Vonshak 2002), and heat (Zushi et al. 2012).

In the Tarim Basin, plant leaves are often exposed to high irradiance. The accumulation of particles on the leaf surface is a common phenomenon. The dust particles are mainly composed of clay and quartz. They are not toxic to plant leaves. The particles may shade the leaf, reducing light absorption. However, the effect of dust on leaf 
Table 1. Parameters of the fast fluorescence rise curves OJIP measured in the morning and at noon and photosynthetic parameters measured at noon for cotton leaves not covered or covered with dust. The values are presented as the means \pm SD. The experiment was conducted in a cotton field in Alar of the Tarim Basin in China in August 2013.

\begin{tabular}{|c|c|c|c|c|c|}
\hline Parameters & Replicates $(n)$ & $\begin{array}{l}\text { Not covered } \\
\text { Morning }\end{array}$ & Noon & $\begin{array}{l}\text { Covered } \\
\text { Morning }\end{array}$ & Noon \\
\hline $\mathrm{PI}_{\mathrm{t}}$ & 13 & $21.4 \pm 5.78$ & $14.5 \pm 7.96$ & $31.6 \pm 9.53$ & $34.6 \pm 3.73$ \\
\hline$\varphi_{\text {Po }}$ & 13 & $0.83 \pm 0.01$ & $0.79 \pm 0.03$ & $0.82 \pm 0.02$ & $0.82 \pm 0.02$ \\
\hline$\psi_{\mathrm{o}}$ & 13 & $0.88 \pm 0.02$ & $0.83 \pm 0.05$ & $0.89 \pm 0.02$ & $0.89 \pm 0.02$ \\
\hline$\varphi_{\text {Eo }}$ & 13 & $0.73 \pm 0.02$ & $0.66 \pm 0.07$ & $0.74 \pm 0.03$ & $0.73 \pm 0.03$ \\
\hline$\delta_{\text {Ro }}$ & 13 & $0.54 \pm 0.05$ & $0.59 \pm 0.06$ & $0.64 \pm 0.05$ & $0.67 \pm 0.03$ \\
\hline$\varphi_{\text {Do }}$ & 13 & $0.17 \pm 0.01$ & $0.21 \pm 0.03$ & $0.18 \pm 0.02$ & $0.18 \pm 0.02$ \\
\hline RC/ABS & 13 & $1.29 \pm 0.12$ & $1.13 \pm 0.11$ & $1.28 \pm 0.22$ & $1.23 \pm 0.24$ \\
\hline$g_{\mathrm{s}}\left[\mathrm{mol}\left(\mathrm{H}_{2} \mathrm{O}\right) \mathrm{m}^{-2} \mathrm{~s}^{-1}\right]$ & 3 & - & $0.19 \pm 0.02$ & - & $0.22 \pm 0.06$ \\
\hline$P_{\mathrm{N}}\left[\mu \mathrm{mol} \mathrm{m}{ }^{-2} \mathrm{~s}^{-1}\right]$ & 3 & - & $22.89 \pm 5.73$ & - & $26.06 \pm 3.62$ \\
\hline$\Phi_{\mathrm{P}}$ & 10 & - & $0.19 \pm 0.08$ & - & $0.27 \pm 0.07$ \\
\hline$\Phi_{\mathrm{NPQ}}$ & 10 & - & $0.28 \pm 0.15$ & - & $0.33 \pm 0.11$ \\
\hline$\Phi_{\mathrm{f}, \mathrm{D}}$ & 10 & - & $0.53 \pm 0.14$ & - & $0.40 \pm 0.13$ \\
\hline
\end{tabular}

photosynthesis depends on the quantity of dust on the leaf surface (Qiu et al. 2009). Heavy accumulation of inert dust (Nanos and Ilias 2007), iron ore dust (Paling et al. 2001), coal dust (Naidoo and Chirkoot 2004), and limestone dust (van Heerden et al. 2007) can produce adverse impacts on the activity of PSII and the $\mathrm{CO}_{2}$ assimilation rate. However, van Heerden et al. (2007) emphasized that light deposition of limestone dust can enhance the electron transport of PSII. This was supported by our results for cotton. Light dust accumulation on the leaf surface can weaken the intensity of PAR, mitigating the damage caused to the photosystem by strong light. On the other hand, the dust particles may cause the changes of wavelength range which penetrates into the leaf, resulting in the photosynthetic variation. In future experiments, the extent of the dust covering on the leaf surface needs to be and the relationships between the dust coating and photosynthesis and stomatal performance needs to elucidated.

\section{References}

Akhlaq M., Sheltami T.R., Mouftah H.T.: A review of techniques and technologies for sand and dust storm detection. - Rev. Environ. Sci. Bio.11: 305-322, 2012.

Campos H., Trejo C., Peña-Valdivia C.B. et al.: Photosynthetic acclimation to drought stress in Agave salmiana Otto ex SalmDyck seedlings is largely dependent on thermal dissipation and enhanced electron flux to photosystem I. - Photosynth. Res. 122: 23-39, 2014.

Force L., Critchley C., van Rensen J.J.S.: New fluorescence parameters for monitoring photosynthesis in plants 1 . The effect of illumination on the fluorescence parameters of the JIP-test. Photosynth. Res. 78: 17-33, 2003.

Gomes M.T.G., da Luz A.C., dos Santos M.R. et al.: Drought tolerance of passion fruit plants assessed by the OJIP chlorophyll $a$ fluorescence transient. - Sci. Hortic.-Amsterdam 142: 49-52, 2012.

Hirano T., Kiyota M., Aiga I.: Physical effects of dust on leaf physiology of cucumber and kidney bean plants. - Environ. Pollut. 89: 255-261, 1995.
In summary, given that over a short-term period, the basic status of the leaf (e.g., the chlorophyll content) remained unchanged, the differences in the photosynthetic activity between the leaves covered and not covered with dust were due to dust accumulation on the leaf surface. Dust retention on the leaf surface reduced the amount of PAR that reached the photosynthetic tissues. Thus, light dust accumulation on leaf surfaces protected the photosynthetic apparatus from high irradiance and even increased photosynthetic activity on a short-term basis. For the leaves not covered with dust, however, high irradiance induced damage related to the photosynthetic reactions as well as light absorption and biochemical pathways of $\mathrm{CO}_{2}$ fixation. Some mechanisms, such as thermal dissipation and enhanced electron flux to PSI, protected the photosynthetic apparatus of leaves not covered with dust under high irradiance.
Humplík J.F., Lazár D., Fürst T. et al.: Automated integrative high-throughput phenotyping of plant shoots: a case study of the cold-tolerance of pea (Pisum sativum L.). - Plant Methods 11: 20,2015

Jiang H.X., Chen L.S., Zheng J.G. et al.: Aluminum-induced effects on photosystem II photochemistry in Citrus leaves assessed by the chlorophyll $a$ fluorescence transient. - Tree Physiol. 28: 1863-1871, 2008.

Lazár D.: Parameters of photosynthetic energy partitioning. - J. Plant Physiol. 175: 131-147, 2015.

Lazár D.: The polyphasic chlorophyll $a$ fluorescence rise measured under high intensity of exciting light. - Funct. Plant Biol. 33: 9-30, 2006.

Li L., Zhou Z., Liang J. et al.: In vivo evaluation of the highirradiance effects on PSII activity in photosynthetic stems of Hexinia polydichotoma. - Photosynthetica 53: 621-624, 2015.

Li M., Ji L., Yang X.: The protective mechanisms of CaHSP26 in transgenic tobacco to alleviate photoinhibition of PSII during chilling stress. - Plant Cell Rep. 31: 1969-1979, 2012. 
Lin Y.C., Mu G.J., Xu L.S. et al.: [Grain size characteristics of the foliar dust on several typical arbors under natural environment in Cele Oasis of southern Xinjiang.] - J. Soil Water Conserv. 6: 241-245, 2015. [In Chinese]

Liu X., Zhong Y., Wang M. et al.: Atmospheric dustfall variation and factor analysis in Tarim Basin. - J. Desert R. 30: 954-960, 2010.

Lu C., Vonshak A.: Effects of salinity stress on photosystem II function in cyanobacterial Spirulina platensis cells. - Physiol. Plantarum 114: 405-413, 2002.

Naidoo G., Chirkoot D.: The effects of coal dust on photosynthetic performance of the mangrove, Avicennia marina in Richards Bay, South Africa. - Environ. Pollut. 127: 359-366, 2004.

Nanos G.D., Ilias I.F.: Effects of inert dust on Olive (Olea europeaea L.) leaf physiological parameters. - Environ. Sci. Pollut. R. 14: 212-214, 2007.

Neves N.R., Oliva M.A., Centeno D.C. et al.: Photosynthesis and oxidative stress in the resting plant species Eugenia uniflora L. exposed to simulated acid rain and iron ore dust deposition: Potential use in environmental risk assessment. - Sci. Total Environ. 407: 3740-3745, 2009.

Paling E.I., Humphries G., McCardle I. et al.: The effects of iron ore dust on mangroves in Western Australia: Lack of evidence for stomatal damage. - Wetl. Ecol. Manag. 9: 363-370, 2001.

Pourkhabbaz A., Rastin N., Olbrich A. et al.: Influence of environmental pollution on leaf properties of urban plane trees, Platanus orientalis L. - Bull. Environ. Contam. Toxicol. 85: 251-255, 2010.

Prusty B.A.K., Mishra P.C., Azeez P.A.: Dust accumulation and leaf pigment concentration in vegetation near the national highway at Sambalpur, Orissa, India. - Ecotox. Environ. Safe. 60: 228-235, 2005.

Qiu Y., Guan D., Song W. et al:: Capture of heavy metals and sulfur by foliar dust in urban Huizhou, Guangdong Province, China. - Chemosphere 75: 447-452, 2009.

Rai A., Kulshreshtha K., Srivastava P.K. et al.: Leaf surface structure alterations due to particulate pollution in some common plants. - Environmentalist 30: 18-23, 2010.

Raven J.A.: The cost of photoinhibition. - Physiol. Plantarum 142: 87-104, 2011

Schansker G., Tóth S.Z., Strasser R.J.: Methylviologen and dibromothymoquinone treatments of pea leaves reveal the role of Photosystem I in the $\mathrm{Chl} a$ fluorescence rise OJIP. Biochim. Biophys. Acta 1706: 250-261, 2005.
Shao Y.: Physics and Modelling of Wind Erosion. Pp: 247. Springer, Dordrecht 2008

Sharifi M.R., Gibson A.C., Rundel P.W.: Surface dust impacts on gas exchange in Mojave Desert shrubs. - J. Appl. Ecol. 34: 837-846, 1997.

Stirbet A., Govindjee: On the relation between the Kautsky effect (chlorophyll $a$ fluorescence induction) and Photosystem II: Basics and applications of the OJIP fluorescence transient. - J. Photoch. Photobio. B 104: 236-257, 2011.

Strasser R.J., Srivastava A., Tsimilli-Michael M.: The fluorescent transient as a tool to characterise and screen photosynthesic samples. - In: Yunus M., Pathre U., Mohanty P. (ed.): Probing Photosynthesis: Mechanisms, Regulation and Adaptation. Pp. 445-483. Taylor and Francis, London 2000.

Strasser R.J., Srivastav, A., Tsimilli-Michael M.: Analysis of the Chlorophyll $a$ fluorescence transient. - In: Papageorgiou G.C., Govindjee (ed.): Chlorophyll a Fluorescence: a Signature of Photosynthesis, Advances in Photosynthesis and Respiration Series. Pp. 321-362. Springer, Dordrecht 2004.

Takahashi S., Badger M.R.: Photoprotection in plants: a new light on photosystem II damage. - Trends Plant Sci. 16: 53-60, 2011.

van Heerden P.D., Krüger G.H., Louw M.K.: Dynamic responses of photosystem II in the Namib Desert shrub, Zygophyllum prismatocarpum, during and after foliar deposition of limestone dust. - Environ. Pollut. 146: 34-45, 2007.

Wilhelm C., Selmar D.: Energy dissipation is an essential mechanism to sustain the viability of plants: The physiological limits of improved photosynthesis. - J. Plant Physiol. 168: 79-87, 2011.

Yang L.P.: [Outlines of Nature Region Programming in Xinjiang.] Pp. 52-75. Science Press, Beijing 1987. [In Chinese]

Zhao Y., Li H., Huang A.: [Relationship between thermal anomalies in Tibetan Plateau and summer dust storm frequency over Tarim Basin, China.] - J. Arid Land 5: 25-31, 2013. [In Chinese]

Zivcak M., Brestic M., Kalaji H.M. et al.: Photosynthetic responses of sun- and shade-grown barley leaves to high light: is the lower PSII connectivity in shade leaves associated with protection against excess of light? - Photosynth. Res. 119: 339354, 2014.

Zushi K., Kajiwara S., Matsuzoe N.: Chlorophyll $a$ fluorescence OJIP transient as a tool to characterize and evaluate response to heat and chilling stress in tomato leaf and fruit. - Sci. Hortic.-Amsterdam 148: 39-46, 2012. 